\title{
Title:Early assessment of ventricular synchronization and function after left bundle-branch-area pacing with right bundle-branch block
}

\author{
Ruohan Zhao ${ }^{1}$, Feng Xiong ${ }^{1}$, Xiaoqi Deng ${ }^{1}$, Shuzhen Wang ${ }^{1}$, Chunxia Liu $^{1}$, Min Xu $^{1}$, \\ Kunyue $\operatorname{Tan}^{1}$, and Xiuxiu Wang ${ }^{1}$ \\ ${ }^{1}$ Chengdu Third People's Hospital
}

December 30, 2021

\begin{abstract}
Aim To evaluate ventricular synchronization and function in patients with right bundle-branch block after left bundle-brancharea pacing (LBBAP) by echocardiography. Methods Forty patients who successfully received LBBAP were selected and divided into the right bundle-branch block group (RBBB group) and the non-RBBB group by pre-operation ECG. Echocardiography and follow-up were performed 1 month after operation. Interventricular synchronization was evaluated by tissue Doppler (TDI), tissue mitral annular displacement (TMAD), and interventricular mechanical delay (IVMD). The ventricular longitudinal strain and the standard deviation of peak time of longitudinal strain were analyzed by two-dimensional speckle tracking imaging (2DSTI) to evaluate intraventricular synchronization and ventricular function. Results (1) The deviation of systolic time to the peak of the tricuspid and mitral valves, namely $\triangle$ PTTV-MV measured by TMAD and $\Delta$ TsTV-MV measured by TDI, were statistically different between the two groups $(\mathrm{P}<0.05)$. (2) Compared with the non-RBBB group, there were no statistically significant differences in longitudinal strain (LS), peak strain time, standard deviation of peak strain time (SDt), and global longitudinal strain (GLS) in the right and left ventricle in the RBBB group ( $\mathrm{P}>0.05)$. Conclusion Echocardiography technology including 2D-STI, TDI, and TMAD can effectively analyze interventricular synchronization, intraventricular synchronization, and ventricular function. Although the movement of the right ventricular myocardium in the RBBB group treatment was slightly later than that of the left ventricular myocardium after LBBAP, LBBAP is still an effective pacing therapy for RBBB patients with pacing indication.
\end{abstract}

\section{Hosted file}

manuscript.doc available at https://authorea.com/users/453225/articles/551125-title-earlyassessment-of-ventricular-synchronization-and-function-after-left-bundle-branch-areapacing-with-right-bundle-branch-block 


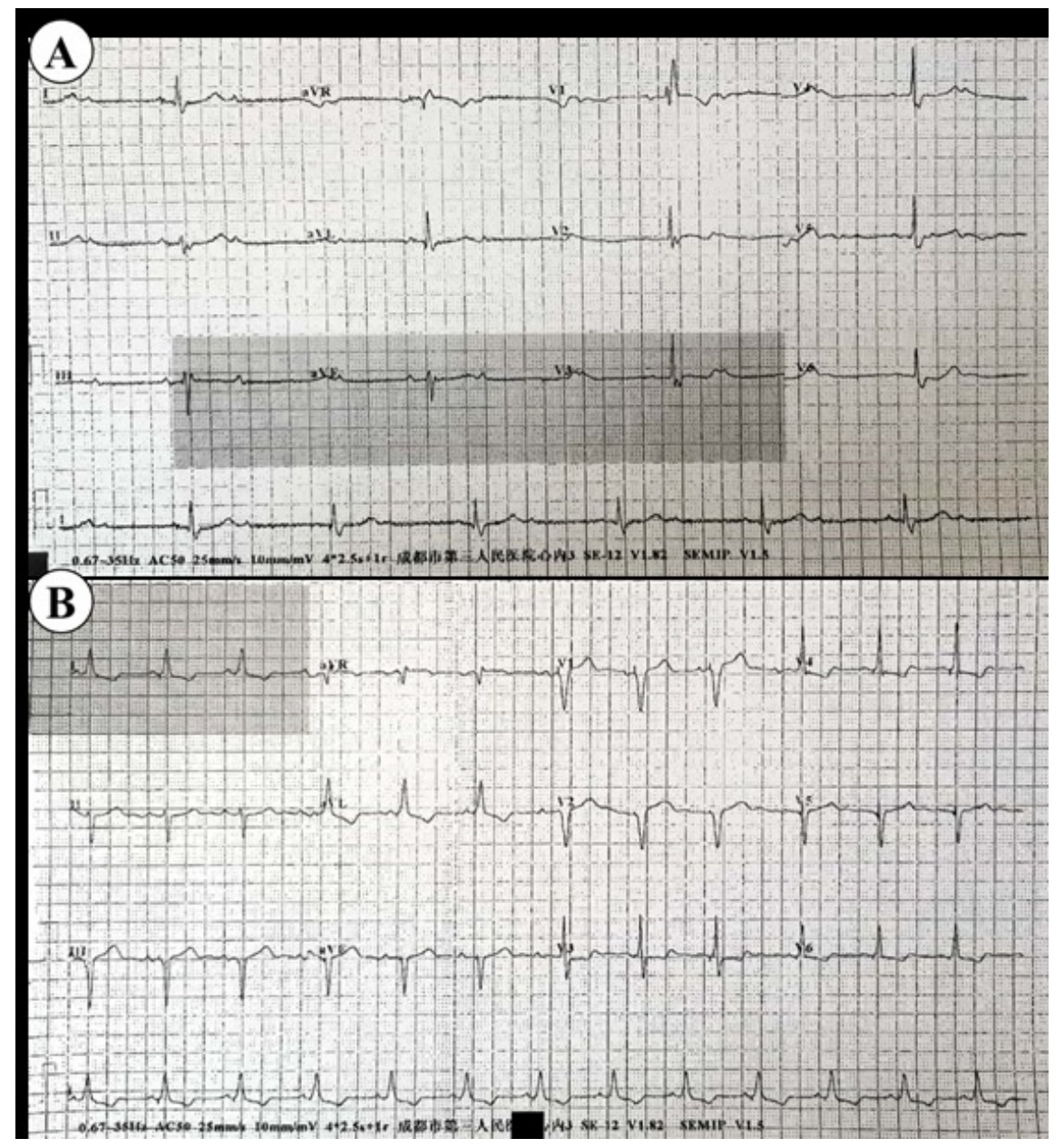



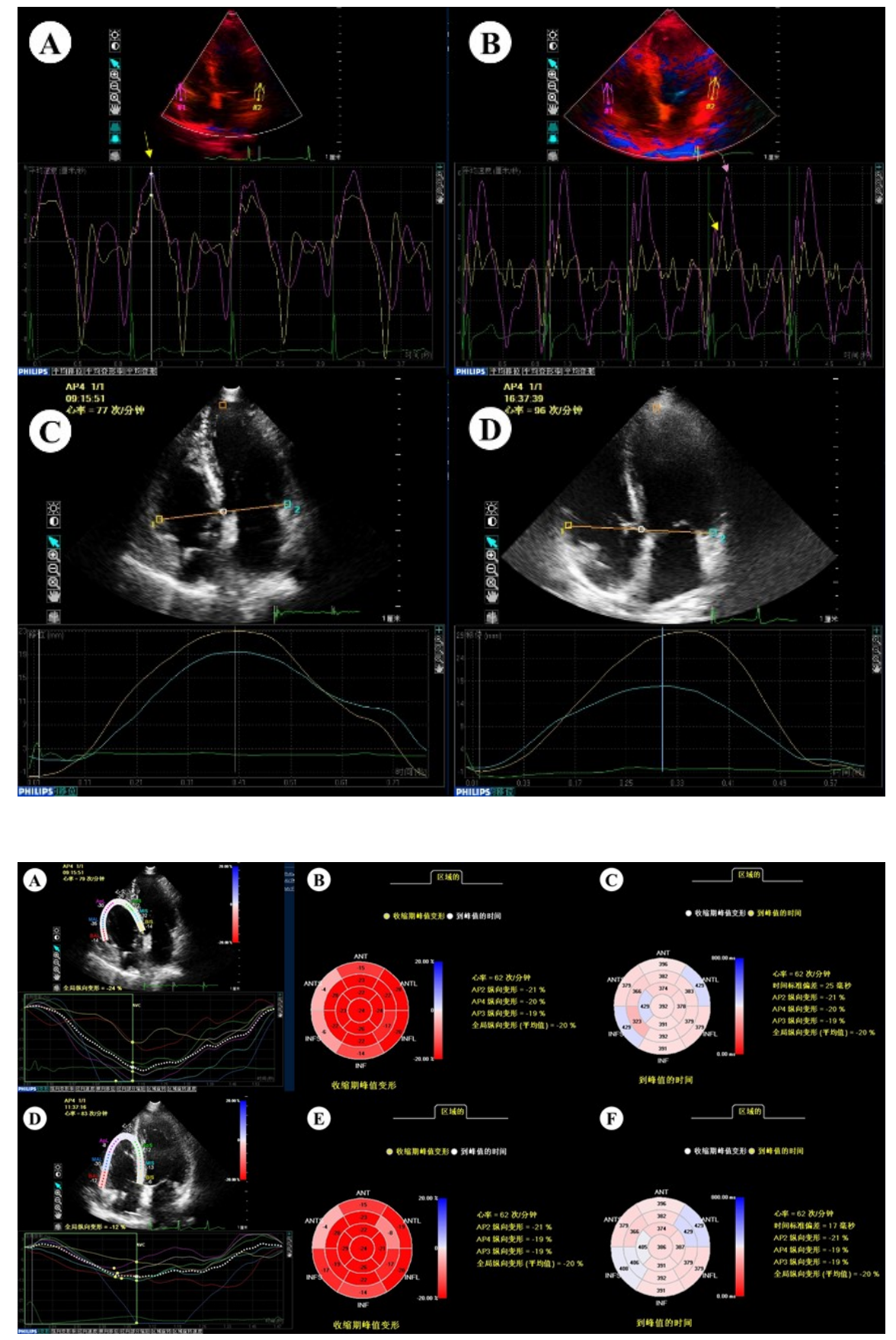

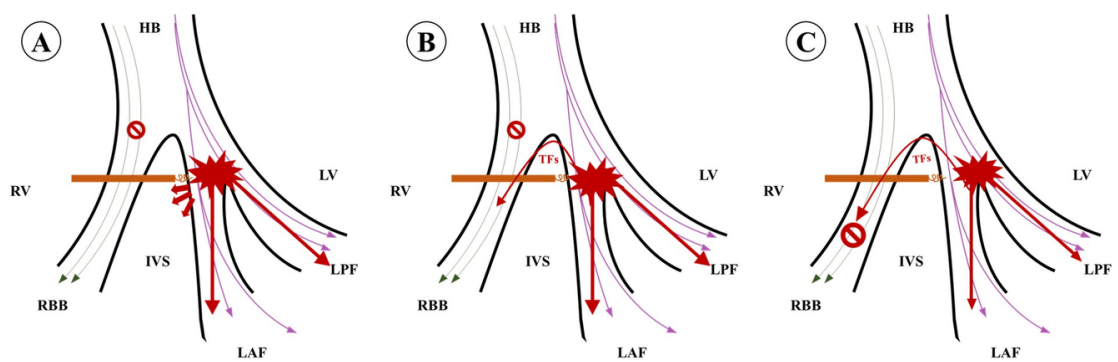

\section{Hosted file}

table.docx available at https://authorea.com/users/453225/articles/551125-title-earlyassessment-of-ventricular-synchronization-and-function-after-left-bundle-branch-areapacing-with-right-bundle-branch-block 